\title{
Prefácio à dissidência: um debate em torno das noções de guerra civil, transgressão e dissidência a partir de Michel Foucault.
}

\author{
Preface to dissent: a debate around the notions of civil war, \\ transgression and dissent from Michel Foucault.
}

\author{
Mateus Thomaz Bayer \\ Universidade Federal do Rio de Janeiro
}

\section{RESUMO:}

Este artigo tem como objetivo explorar os efeitos da autocrítica realizada por Michel Foucault frente à noção de transgressão em seu curso A Sociedade Punitiva (1972-1973) e seu deslocamento analítico e estratégico para a noção de dissidência. Nota-se que esta passagem se articula à emergência de uma concepção particular da "guerra civil" como campo de inteligibilidade das lutas em torno do poder. Realizada no ano seguinte, em $O$ Poder Psiquiátrico (1973-1974), sua leitura política do "fenômeno histérico" do século XIX enquanto luta antipsiquiátrica servirá de exemplo privilegiado no sentido de adensar a dimensão conceitual que pode ser extraída da utilização contextualizada do termo "dissidência". Entende-se que o esforço, próprio ao presente trabalho, para se pensar um conceito de dissidência a partir de Foucault pode estabelecer algumas pistas importantes para a reflexão sobre a singularidade teórica e política da genealogia foucaultiana.

Palavras-chave: transgressão; dissidência; guerra civil; genealogia.

\begin{abstract}
:
This article aims to explore the effects of the self-criticism carried out by Michel Foucault in the face of the notion of transgression in his course The Punitive Society (1972-1973) and his analytical and strategic displacement to the notion of dissent. It is noted that this passage is articulated with the emergence of a particular conception of the "civil war" as a field of intelligibility of the struggles around power. Held the following year in The Psychiatric Power (1973-1974), his political reading of the "hysterical phenomenon" of the nineteenth century as an anti-psychiatric struggle will serve as a privileged example in order to deepen the conceptual dimension that can be extracted from the contextualized use of the term "dissent". It is understood that the effort, proper to the present work, to think about a concept of dissent from Foucault can establish some important clues for the reflection on the theoretical and political singularity of Foucault's genealogy.
\end{abstract}

Key-words: transgression; dissent; civil war; genealogy.

DOI:10.12957/mnemosine.2021.62173 


\section{Introdução}

Ao situar o curso A Sociedade Punitiva (1972-1973), Bernard Harcourt destaca o fato de este ter sido pronunciado "no apogeu de um dos períodos de maior militância de Foucault em torno das questões penais na França" (HARCOURT, 2015: 243). É neste mesmo movimento que encontramos no referido curso também uma série de rupturas de Foucault em relação ao pensamento político que ele próprio vinha estabelecendo até então. Se o curso do ano anterior (Teorias e Instituições Penais - 1971-1972) foi dedicado à dimensão repressiva da penalidade, logo nas primeiras páginas de A Sociedade Punitiva encontramos justamente uma reviravolta em relação a esta concepção e a tudo que a ela possa estar relacionada. Isso se dará de forma muito explícita por parte de Foucault, uma vez que o que encontramos nas referidas páginas é não somente uma crítica à noção de exclusão (par condicionante das análises políticas pautadas numa concepção repressiva do poder), como também uma problematização em torno da própria noção de transgressão, que teria sido extremamente cara ao pensamento foucaultiano em seus escritos da década de 1960. Como se notará adiante, para os fins do presente trabalho, a dimensão dessa importância será explorada a partir de sua prestigiosa presença no primeiro prefácio de História da Loucura na Idade Clássica de 1961; e - mais diretamente - no importante artigo escrito em homenagem a Georges Bataille e publicado por Foucault em 1963: "Prefácio à Transgressão". Sobre este último, Diogo Sardinha, ao analisar um registro problemático comum entre este artigo e os escritos de Foucault do início dos anos 1980, pontuará seu lugar decisivo nos seguintes termos: "De onde a força exemplar desse artigo que, a propósito de Bataille, recobre finalmente um leque de problemas, com os quais Foucault jamais deixou de se debater, desde aquele da localização e do estabelecimento dos limites do ser até os da crítica, da ética, da sexualidade e do sujeito" (SARDINHA, 2010: 189-190)

A princípio, portanto, a questão proposta aqui será a de compreender em que medida a crítica que Foucault estabelece ao conceito de transgressão (até então significativamente utilizado por ele próprio) se conecta a seu entendimento do funcionamento do poder a partir da sua compreensão da noção de guerra civil. Entendese que, a partir desta trajetória, é possível também estabelecer em que medida a noção de dissidência - que irá se opor termo-a-termo à de transgressão - pôde ter uma entrada estratégica em suas aulas de 1972-1973 no sentido de acompanhar as inovações teóricas 
em torno da questão do poder e dos jogos de luta e revide que vemos descritos no referido curso.

A partir das determinações dessa diferença, é possível estabelecer uma espessura conceitual advinda do uso do termo dissidência, uma vez que este uso irá implicar uma passagem do problema do "interdito" ao problema das conexões do poder. Tal passagem implica também um modo completamente distinto de se compreender o que são os atos de resistência ao poder.

Na busca de um exemplo privilegiado do que poderíamos chamar de um "efeito de ressonância" dessa passagem, este trabalho abordará - nos termos de uma dimensão conceitual da dissidência - a leitura política que Foucault faz do "fenômeno histérico" do século XIX tal como ele é apresentado em O Poder Psiquiátrico - curso proferido no Collège de France entre os anos de 1973-1974; portanto, exatamente na sequência de $A$ Sociedade Punitiva. O problema da simulação imposto pelas histéricas à psiquiatria teria atacado justamente a conexão entre poder, verdade, realidade e cura que se colocava no cerne da constituição do poder psiquiátrico. Tem-se, portanto, a tese levantada por Foucault de que o fenômeno histérico que se proliferou nos asilos franceses no século XIX foi, própria e verdadeiramente, o primeiro movimento antipsiquiátrico de que se tem notícia.

Adensada a dimensão conceitual da dissidência, vislumbra-se então não apenas a possibilidade de interrogar suas ressonâncias, como também a de realizar o projeto mais amplo de uma cartografia das dissidências a ser efetuada em torno da experiência teórica e política que foi própria à singularidade da genealogia foucaultiana.

\section{Crítica à noção de exclusão}

Nas primeiras páginas de A Sociedade Punitiva, Foucault estabelece um diálogo estratégico com Lévi-Strauss para destacar a particularidade de seus argumentos. Aponta que, em Tristes Trópicos, Lévi-Strauss afirma que para se livrar de um indivíduo considerado hostil ou perigoso as sociedades teriam pelo menos dois modos de fazê-lo. Num primeiro caso, teríamos a solução antropofágica que consistiria em assimilar e, assim, neutralizar a força perigosa contida no indivíduo a partir de um mecanismo de absorção. Noutro caso, teríamos a solução da antropoemia (derivada do grego emein: vomitar) que consistiria num mecanismo inverso: não o de neutralizar por absorção, mas por expulsão ou isolamento, estabelecendo um corte no contato com a humanidade a partir de estabelecimentos destinados a este uso. Assim, temos não mais a assimilação, 
mas a expulsão. E isto de modo tal que, as sociedades ocidentais, portanto, seriam desta última espécie.

Evidentemente, é sabido a larga escala dos usos do conceito de "exclusão" para caracterizar os efeitos do poder nessas sociedades. Foucault destaca como esta noção teria servido, por um longo tempo, para caracterizar de modo vago o estatuto conferido aos delinquentes, às minorias étnicas, religiosas ou sexuais, e a todos os indivíduos que ficam de fora dos circuitos de produção e de consumo. Ora, trata-se de uma noção que em dado momento teria sido útil para solapar o jogo de ocultação que noções como a de "desvio", "anomalia" e "inadaptação" exerceram no mascaramento dos procedimentos pelos quais as sociedades excluíam os indivíduos para apresentá-los, em seguida, como anormais ou desviantes. Assim, "foi importante a função de inversão crítica da noção de exclusão em relação às noções psicossociológicas de desvio e inadaptação" (FOUCAULT, 2015: 4).

Entretanto, esta noção se mostra insuficiente para rastrear as lutas, estratégias e táticas em relação aos jogos de poder em todas as suas articulações. E isto na medida em que o que ela nos fornece é apenas o "efeito representativo geral” dessas lutas. Ou seja: o indivíduo excluído só pode aparecer como não-comunicante em relação aos demais fatores de organização exteriores a ele na medida em que é destacado como "representação social" em descontinuidade com uma norma.

Essa noção de exclusão parece-me, portanto, permanecer dentro do campo das representações e não levar em conta - não poder, por conseguinte, levar em conta nem analisar as [lutas], as relações, as operações especificadas do poder a partir das quais, precisamente, se faz a exclusão. A exclusão seria o efeito representativo geral de várias estratégias e táticas de poder, que a própria noção de exclusão não pode atingir por si só. Além disso, essa noção possibilita responsabilizar a sociedade em geral pelo mecanismo por meio do qual o excluído acaba excluído. Em outras palavras, perde-se não só o mecanismo histórico, político, de poder, como também se corre o risco de ser introduzido em erro no que se refere à instância que exclui, pois a exclusão [parece] referir-se a algo como um consenso social que rejeita, ao passo que por trás disso talvez haja várias instâncias perfeitamente especificadas, por conseguinte, definíveis, de poder que são responsáveis pelo mecanismo de exclusão. (FOUCAULT, 2015: 5)

Daí as discordâncias de Foucault em relação a Lévi-Strauss, uma vez que este elenca os fatores de exclusão e assimilação como técnicas perfeitamente opostas. O que é indicado com essa crítica é o fato de que há continuidades que podem ser determinadas entre os mecanismos que incluem/assimilam e os que excluem/expulsam. Haveria, então, um jogo muito mais complexo entre antropofagia e antropoemia do que as suas representações nos apresentam. Os jogos de exclusão não estão, em absoluto, em oposição às técnicas de assimilação - e isto de modo que: "Não há exílio, reclusão que, 
além daquilo que caracterizamos de modo geral como expulsão, deixe de comportar uma transferência, uma reativação desse mesmo poder que impõe, coage e expulsa" (FOUCAULT, 2015: 5).

Por exemplo, temos que o hospital psiquiátrico é o lugar que exclui o indivíduo do restante do tecido social, mas é também o lugar de onde se secreta racionalidades que são reabsorvidas pelo seu exterior na forma de discursos científicos e de discursos de saber sobre a loucura e a razão. Ora, isso faz com que o funcionamento "interno" seja convertido em formas de saber que tem sua circulação social mais ampla, o que situa continuamente o hospital psiquiátrico numa rede "exterior" de racionalidades a partir das quais ele irá se alocar com determinadas funções e, por consequência, será também modificado por esses jogos.

Aquilo que é vigilância, em termos de relações de poder no interior do hospital, se tornará observação científica no discurso do médico, pelo próprio fato de que o médico, por um lado, ocupa uma posição de poder dentro do hospital e, por outro, funciona como alguém que profere e tem o direito de proferir um discurso científico fora do hospital. Aquilo que era classificação, instrução, nos termos da relação de autoridade interior ao hospital, será convertido em diagnóstico ou prognóstico, em nosografia na linguagem do médico, que, quando está fora do hospital, funcionará como sujeito de um discurso científico. [...] Haveria ao mesmo tempo transferência do interior do hospital para o seu exterior e conversão de uma relação de poder numa relação de saber. (FOUCAULT, 2015: 6)

Assim, é como se a antropoemia pudesse ser convertida em um tipo de antropofagia por todo um sistema de transferências e "ingestões". Relação esta, então, que só pode surgir na medida em que se descola a análise das representações da exclusão para a identificação das táticas e das estratégias que lhes são subjacentes.

\section{Crítica à noção de transgressão}

Nesse mesmo movimento, seria preciso também estabelecer a crítica de uma noção que teve seu sucesso relativo ao da noção de exclusão: trata-se da noção de transgressão.

A noção de transgressão durante certo período desempenhou [um papel] mais ou menos comparável ao [da noção] de exclusão. Também ela permitiu uma espécie de inversão crítica, importante por ter possibilitado evitar noções como as de anomalia, culpa, lei. Autorizou uma inversão do negativo em positivo, do positivo em negativo. Possibilitou ordenar todas essas noções não mais em relação à noção, maior, de lei, mas à de limite. (FOUCAULT, 2015: 7, grifo do autor)

Tal noção, portanto, não indicaria apenas uma passagem do lícito ao ilícito, mas sim a passagem para "aquilo que não tem regra" e que, por isso mesmo, não pode ser 
representado. A noção de transgressão encarna, assim, uma relação com o limite e com o irrepresentável.

Em 1963, num importante artigo escrito em homenagem a Georges Bataille e denominado "Prefácio à Transgressão", Foucault evidenciará nitidamente essa conjunção: “A transgressão é um gesto relativo ao limite; é aí, na tênue espessura da linha, que se manifesta o fulgor de sua passagem, mas talvez também sua trajetória na totalidade, sua própria origem. [...] O limite e a transgressão devem um ao outro a densidade de seu ser" (FOUCAULT, 2006d: 32). Tal relação, portanto, não é de uma oposição pura e simples (como o proibido se opõe ao permitido), mas sim uma "relação em espiral que nenhuma simples infração pode extinguir”. Foucault usa o exemplo do relâmpago para ilustrar o que pretende situar, pois este - em seu clarão - concede densidade àquilo que nega (a escuridão da noite) justamente pela vivacidade de sua claridade que de forma imediata "perde-se no espaço que ela assinala com sua soberania e por fim se cala, tendo dado um nome ao obscuro" (FOUCAULT, 2006d: 33). É nessa medida que a transgressão, na verdade, "não opõe nada a nada", recusando-se à toda dialética, a todo triunfo e a toda "positividade" que tenta retê-la em algum conteúdo.

É este o jogo, por exemplo, que constitui o norte do projeto de História da Loucura indicado em seu primeiro prefácio: estabelecer uma "história dos limites" na qual o questionamento pudesse se voltar às estruturas da experiência trágica da loucura "antes de toda captura pelo saber" de modo que, assim, pudéssemos "confrontar as dialéticas da história com as estruturas imóveis do trágico" (FOUCAULT, 2006: 155). Projeto este que consistiria na seguinte consideração:

No centro dessas experiências-limites do mundo ocidental explode, é evidente, a do próprio trágico - tendo Nietzsche mostrado que a estrutura trágica a partir da qual se faz a história do mundo ocidental não é outra coisa senão a recusa, o esquecimento e a recaída silenciosa da tragédia. Em torno desta, que é central já que ela enlaça o trágico à dialética da história na própria recusa da tragédia pela história, muitas outras experiências gravitam, cada uma, nas fronteiras de nossa cultura, traça um limite que significa, ao mesmo tempo, uma divisão originária (FOUCAULT, 2006: 155)

Dessa forma, a partir da análise das experiências-limites seria possível avaliar os gestos pelos quais uma cultura, no lance mesmo em que constitui para ela um "Exterior" impossível de ser representado em seus termos, designa com a mesma força o que será o cerne de seus valores. O jogo denso da transgressão e do limite permitiria, portanto, este tipo de análise que estará presente em História da Loucura. O caso já não é o mesmo em A Sociedade Punitiva, uma vez que: 
[...] acredito que as noções de exclusão e transgressão devem ser consideradas agora instrumentos que tiveram sua importância histórica: durante determinado período, elas foram inversores críticos no campo da representação jurídica, política e moral; mas esses inversores continuam alinhados com o sistema geral das representações contra as quais se tinham voltado. Parece-me que as direções indicadas pelas análises feitas em termos de exclusão e transgressões precisam ser seguidas em novas dimensões, nas quais já não se falará em lei, regra, representação, mas em poder em vez de lei, em saber em vez de representação. (FOUCAULT, 2015: 7, grifo meu)

É neste sentido que Foucault buscará estabelecer suas análises não no campo das representações jurídicas, morais ou religiosas da punição que a sustentam ou justificam, tampouco no domínio das "grandes funções" que exercem (exclusão ou assimilação), mas sim ao nível das táticas penais. Trata-se de buscar estabelecer as relações de poder que efetivamente se põem em ação nessas táticas, sendo que o que ocupará o primeiro plano aí serão as formas de luta, revide, articulação, etc. Não se trata, portanto, do conjunto lógico das representações políticas, mas sim do ato e do movimento pelo qual o poder se encontra exercido na sua dimensão de batalha contínua, ainda não estabilizado inteiramente num regime representacional qualquer. Como diz Foucault: "Em outras palavras, gostaria de abordar essas táticas como analisadores das relações de poder, e não como reveladores de uma ideologia" (FOUCAULT, 2015: 12-13). É dessa forma, pois, que se busca estabelecer um registro de acesso aos jogos múltiplos pelos quais, nunca sociedade, organizam-se as lutas em torno do poder.

\section{Introdução à guerra civil}

É neste registro dos jogos do poder ao nível das táticas que o conceito foucaultiano de guerra civil irá operar. Este conceito busca abarcar o que seria "o estado permanente a partir do qual é possível e é preciso compreender diversas dessas táticas de luta”. A este ponto, afirmará que:

A guerra civil é a matriz de todas as lutas pelo poder, de todas as estratégias do poder $e$, por conseguinte, também a matriz de todas as lutas a propósito do poder e contra ele. É a matriz geral que possibilitará compreender a instauração e o funcionamento de determinada estratégia de penalidade: a da reclusão. O que vou tentar mostrar é o jogo, na sociedade do século XIX, entre uma guerra civil permanente e as táticas opostas do poder. (FOUCAULT, 2015: 13-14).

É preciso, contudo, estabelecer com exatidão de que fala Foucault quando fala de "guerra civil". Sua estratégia argumentativa tem como ponto de diferenciação justamente aquilo que denuncia como um equívoco de certa tradição do pensamento político que equivale guerra civil e guerra de todos contra todos. Para Foucault, há uma completa 
inexistência de relação entre ambas. Seu regime de equivalência só pode ser estabelecido a partir de uma tradição do pensamento político que tem em Hobbes uma das figuras mais emblemáticas.

O que teríamos na teoria hobbesiana da guerra civil é que esta é, de alguma maneira, a volta da guerra de todos contra todos. É certo que Hobbes chega a dizer em seu Leviatã que talvez nunca tenha, na verdade, existido um estado de guerra como esse, mas, para aquele que um dia buscar saber como seria o funcionamento da guerra de todos contra todos, os momentos em que a humanidade estabeleceu guerras civis seria o índice privilegiado para sua compreensão (o estado de guerra dos "selvagens das Américas", por exemplo, seria um exemplo limitado e historicamente determinado disso).

A guerra civil, portanto, é um caso historicamente determinado de ressurgência da guerra de todos contra todos. É uma espécie de modelo epistemológico a partir do qual deve ser possivel decifrar esse estado de guerra de todos contra todos, e necessário para compreender os fundamentos e o funcionamento do soberano. (FOUCAULT, 2015: 24-5).

Assim, o que vemos em Hobbes é uma aproximação das duas noções. Mesmo que haja críticas à teoria hobbesiana da guerra de todos contra todos, Foucault indicará que o que será negado nessas críticas é o suposto modelo do estado de natureza da humanidade aí embutido. Não será aí criticado, portanto, justamente a equiparação entre esses dois modelos de guerra. A este respeito, Foucault buscará mostrar como não há fundamento de equivalência possível para se afirmar a continuidade entre ambas as guerras - sendo que nesse mesmo movimento, acaba por formular seu conceito e compreensão em torno da noção de "guerra civil".

Primeiramente, então, é preciso responder a seguinte pergunta: qual a ideia que Hobbes tem da guerra de todos contra todos? Esta guerra, nas palavras de Foucault, é uma guerra de todos os indivíduos em sua qualidade mesma de indivíduos, ou seja, é uma dimensão natural e universal das relações entre os indivíduos, considerados então como portadores de uma disponibilidade permanente para a guerra de todos contra todos. É justamente o fato de que todos seriam a princípio iguais em objetos e objetivos o que implica um princípio de rivalidade entre os homens, pois se todos se equivalem em meios para obter o que desejam, não há como desejar algo comum sem que isso implique ao mesmo tempo que os homens se tornem inimigos. Assim, é dessa igualdade, portanto, que decorre a substitutibilidade dos homens entre si - eis então a "rivalidade originária" que irá marcar essa condição. Por outro lado, mesmo que haja "tudo para todos", nunca haverá a certeza de que o outro não venha a lhe substituir em decorrência dessa igualdade 
generalizada. É que todo o gozo e toda posse, portanto, tornam-se precárias precisamente em função dessa igualdade. Aqui, soma-se à rivalidade o sentimento de desconfiança como a segunda dimensão da guerra de todos contra todos.

É apenas com a vitória de um dos combatentes e seu decorrente aumento de poder que se poderá cessar a desconfiança e deter a rivalidade, uma vez que esse aumento implica que os outros não buscarão mais substituí-lo. Goza-se com tranquilidade e detémse posses seguras na medida em que se é respeitado; respeito este que tem como condição uma diferenciação primeira do estado de igualdade. Aquele que vence passa a expor suas glórias, de modo que o crescimento de poder faz com que os homens entrem nos sistemas de signos e marcas destinados a tornar visíveis o poder de um deles em relação aos demais. Eis o que Hobbes chama de "glória": a capacidade de impor respeito por meio de signos externos destinados a frear todos aqueles que teriam a pretensão de substituir o vencedor.

Glória, rivalidade e desconfiança, então, são três dimensões inteiramente individuais que constituem a dinâmica própria da guerra de todos contra todos. Assim, tal guerra é a consequência das paixões naturais dos homens enquanto indivíduos. Não é a formação de um grupo que anularia isso, visto que mesmo em pequenos grupos como as famílias as ações podem continuar sendo guiadas por apetites individuais e por julgamentos daí decorrentes. Dessa forma, aponta Foucault, "não é do efeito de grupo, de uma espécie de interesse transitório e mútuo, que os homens podem esperar algo como a saída da guerra" (FOUCAULT, 2015: 26). É preciso que haja a instauração de um novo tipo de ordem: a ordem civil que ocorre a partir do surgimento do soberano. É o soberano que põe fim à guerra de todos contra todos, na medida em que ele emerge nos processos pelos quais os indivíduos transferem seus poderes e suas vontades a um único indivíduo e a uma única vontade. Cessa-se a guerra, portanto, por transferência e concentração de poder. De modo inverso, quando o poder soberano se dissocia ou se atenua, aos poucos veríamos voltar os índices desse estado de guerra - daí, inclusive, que a guerra civil pode ser considerada o signo contemporâneo à sua época do imemoriável estado de guerra de todos contra todos. A guerra civil, desse modo, coloca-se aí como uma forma de "estado terminal" da dissolução do soberano na mesma medida que a guerra de todos contra todos é o estado inicial de onde ele se constitui.

Foucault vai se opor a Hobbes propondo uma outra concepção de guerra civil absolutamente distinta. Primeiramente, dirá que a guerra civil não é uma virtualidade essencial dos indivíduos, uma vez que é primordialmente confronto de coletivos. Ou seja, 
não há guerra civil que não seja um confronto entre tipos de coletivos (parentes, religiões, etnias, comunidades linguísticas, classes, etc.). E isto de modo que é sempre por esses elementos coletivos e plurais que nasce, se desenvolve e se exerce a guerra civil.

Portanto, ela não tem em absoluto a dimensão natural das relações entre indivíduos na qualidade de indivíduos: os atores da guerra civil são sempre grupos na qualidade de grupos. Ademais, a guerra civil não só põe em cena elementos coletivos como também os constitui. (FOUCAULT, 2015: 27).

Não se trata, assim, de um processo de "subida e descida" que vai da individualização das forças no soberano ao estado de natureza e de igualdade geral entre os indivíduos, mas sim de um processo que tem personagens coletivos e que, além do mais, promove o aparecimento de novas coletividades que não tinham vindo à tona até então.

Por outro lado, ao contrário do que é admitido pela teoria política tradicional pautada num prolongamento das formulações hobbesianas, a guerra civil não é anterior ao poder político e tão pouco marca o momento de seu desaparecimento. Ela não está numa relação de exclusão com o poder, uma vez que seu próprio desenrolar se dá no “teatro do poder". A guerra civil se dá no cerne mesmo do poder político constituído, uma vez que aí vemos seu jogo se dar no sentido da manutenção, conquista, confiscação ou transferência do poder. A guerra civil, portanto, não é o ponto de anulação do poder político, mas sim seu ponto de apoio.

Assim, a guerra civil não pode em caso algum ser considerada algo exterior ao poder, interrompido por ele, mas sim uma matriz em cujo interior os elementos do poder atuam, reativam-se, dissociam-se, mas no sentido de que algumas partes se dissociam umas das outras, sem no entanto perderem sua atividade, de que o poder se reelabora, retoma formas antigas com uma forma mítica. Não há guerra civil sem trabalho de poder, trabalho com o poder. (FOUCAULT, 2015: 30, grifo meu)

Os procedimentos da guerra civil, portanto, não são necessariamente uma ameaça ao chamado "poder estabelecido", uma vez que ela o habita de dentro.

[...] seria possível mostrar que a guerra civil é, ao contrário, aquilo que assombra o poder: assombra não no sentido de causar medo, mas no de que a guerra civil habita, permeia, anima e investe o poder integralmente. [...] Encontra-se os signos disso, na forma da vigilância, da ameaça, da posse da força armada, enfim, de todos os instrumentos de coerção que o poder efetivamente estabelecido adota para exercer-se. O exercício cotidiano do poder deve poder ser considerado uma guerra civil: exercer o poder é de certa maneira travar a guerra civil, e todos esses instrumentos, essas táticas, podem ser distinguidas, essas alianças devem ser analisáveis em termos de guerra civil. (FOUCAULT, 2015: 30-31, grifo meu) 
É dessa forma que a noção de guerra civil como o registro a partir do qual Foucault entenderá as relações de poder ao nível das táticas exibirá todo um novo vocabulário muito distinto daquele que dava sustentação às noções de exclusão e, especialmente, à de transgressão. Não mais a questão do limite a ser transgredido, mas dos jogos de distribuição, alianças, filiações fragmentárias, dispersões táticas, etc. O limite se espalha e se esvai em toda uma heterogeneidade tática que exigirá, agora, outra terminologia que não a da transgressão para a compreensão deste novo jogo a ser jogado.

\section{A genealogia do poder penitenciário}

Podemos traçar as pistas deste novo vocabulário político, ainda em A Sociedade Punitiva (1972-1973), a partir do que podemos chamar de uma genealogia do elemento penitenciário no campo das táticas penais da modernidade.

Dentre as formas de apresentar a emergência do sistema penitenciário muitas narrativas históricas apontam para as relações desta com a vida em celas que constituíam o hábito das instituições monásticas - como se se tratasse aí de um processo de "laicização" de um mecanismo de raízes estritamente religiosas. Entretanto, é preciso questionar em que medida a forma-prisão efetivamente passa ou não pela história dessas comunidades conventuais. Foucault apontará que há uma série de objeções que podemos levantar a este respeito. A primeira delas é que a clausura monástica se constituiu historicamente mais como um lugar protegido em relação ao mundo exterior do que um instrumento para impedir a liberdade de alguém ao acesso deste mesmo mundo. Desse modo, trata-se de um mecanismo em que "o mundo é que é fechado para o lado de fora"; e isto de modo que "há, portanto, uma heterogeneidade essencial entre a reclusão punitiva e a clausura monástica" (FOUCAULT, 2015: 79). O que se tem então é muito mais uma condição para que haja a devida ascese por parte do monástico do que propriamente uma punição que o enclausura numa arquitetura celular. O que o recolhimento garante, assim, é o valor de penitência a um castigo autoimposto por parte do monástico.

O que veio a ser a prisão no sistema penal, dessa forma, não se mostra vinculada à clausura monástica, o que não quer dizer, aponta Foucault, que ela não tenha uma matriz religiosa em sua história. Entretanto, esta matriz precisa ser traçada por outros lugares e outras vias, por meios que são "não só estranhos como também perfeitamente hostis à forma monástica" (id: 80). A tese de Foucault é que a encontramos de forma nascente nas comunidades anglo-saxônicas nos séculos XVII e XVIII, especialmente a sociedade dos quakers que, dissidentes e hostis ao sistema penal inglês, foram cruciais para a 
constituição de um inédito modelo penitenciário nos Estados Unidos pós-independência. O sistema penal inglês do referido período é considerado historicamente um dos mais "selvagens e sangrentos" da história europeia na medida em que "havia na Inglaterra 313 a 315 condutas capazes de levar alguém à forca, ao cadafalso, 315 casos punidos com a morte". (FOUCAULT, 2011: 80)

Avessos à pena de morte, as comunidades quarker dissidentes, ao desembarcarem nos EUA, buscaram implementar um novo código penal em que esta não figurasse entre as principais penas. Até a guerra da independência estado-unidense tais comunidades esbarravam na administração inglesa das colônias. Este contexto, com a independência da Pensilvânia, foi modificado a ponto de que uma das primeiras medidas a serem tomadas teria sido justamente a limitação da pena de morte e o estabelecimento de um novo estatuto punitivo no qual, ao lado das mutilações, da chibata e dos trabalhos públicos, figurasse algo como a prisão. Nas indicações de Foucault, a prisão teria rapidamente adquirido primazia em relação às demais formas; e isto de modo que, em 1790 a pena de morte passa a ser aplicada apenas em um ou dois casos, sendo a prisão a pena fundamental deste novo sistema penal. Eis então o processo histórico que permite a afirmação foucaultiana de que: “[...] se é verdade que a forma-prisão não pode ser derivada das teorias penais de Beccaria, Brissot, etc., como instituição e como prática ela é derivável da concepção quaker de religião, moral e poder.” (FOUCAULT, 2015: 81).

Religião, moral e poder sem dúvidas se colocam no cerne desta transformação. Aqui, é preciso que a relação entre esses elementos na concepção quaker seja explicada. Foucault aponta que para tais comunidades religiosas, o poder político se exerce - e só pode se exercer - na medida em que se aplica como uma força de coerção moral. Assim, "o poder deve ser moral, e, para além dessa moral do poder, deve ser banida qualquer política" (FOUCAULT, 2015, p.81). Em todo caso, a noção fundamental que justifica a atuação do poder é a própria noção religiosa de "mal".

[...] é só porque há mal e malvados que o poder se justifica suprimindo-os, e, em última análise, realizada essa supressão dos malvados, ele precisa se auto suprimir; [...] $O$ caráter central do mal em relação à organização política é um dos fundamentos da concepção quaker da política. (FOUCAULT, 2015: 81)

Ora, tal forma de definição do que é a infração é absolutamente distinta dos reformadores penais clássicos como Beccaria, por exemplo. O punível, aqui, é acima de tudo o mal em sua concepção religiosa. Se a batalha contra algo tão poderoso quanto o mal pode estar na mão dos homens, isso ocorre na medida em que, sendo o mal universal, 
a salvação - na concepção quaker - também o é. Assim, na medida em que Deus não se retirou de ninguém, qualquer um pode reencontrá-lo e, além da salvação individual, pode também reconduzir o próximo ao bem e à luz.

Todos esses princípios se encontram num texto de 1796 sobre as prisões da Filadélfia que é apresentado por Foucault como parte de seu argumento. De autoria do duque de La Rochefoucauld-Liancourt, um educador e reformista social partidário da abolição da escravidão, o texto (algo como um inquérito sobre o funcionamento das prisões) indica como estas se esforçam em pôr para funcionar um modelo no qual o prisioneiro possa esquecer seus antigos hábitos e apagar de sua alma as paixões errantes de seu passado. Incluía-se aí, por exemplo, uma reformulação absoluta da alimentação para que seu sangue possa ser renovado, assim como uma reclusão total do detento que favoreça ao reconhecimento e reflexão deste sobre sua culpa. Apenas posteriormente o detento pode, novamente, ouvir a palavra de um outro - no caso, os inspetores - que então poderão promover sua conversão e reconciliação consigo mesmo.

É a propósito deste tipo de instituição que vemos surgir o termo "penitenciário" no sistema penal. O surgimento da questão da penitência não se dá, contudo, senão por uma rede heterogênea onde vemos que "de um lado tem-se um princípio judiciário que é o da pena como consequência da infração e proteção da sociedade; por outro lado, tem-se um princípio moral da pena que seria processo de penitência em decorrência de uma culpa" (FOUCAULT, 2015: 83). Esta heterogeneidade acarretou, segundo Foucault, uma série de consequências.

A primeira delas é que se trata, aí, do primeiro enxerto real da moral cristã no sistema de justiça criminal. Enquanto se definia o litígio apenas como algo a ser reparado em seus danos à sociedade, tem-se um sistema penal que funciona por vias absolutamente heterogêneas aos modelos cristãos. Entretanto, é importante compreender que tal a articulação entre o jurídico e a moral cristã não se deu no nível "alto" dos princípios, mas no nível mesmo das práticas penais. Assim:

Não foi em virtude de uma penetração ideológica que a consciência cristã irrompeu no sistema penal. Foi por baixo, no último estágio do processo penal: prisão, punição. Foi pela invasão do penal e do jurídico inteiro pelo penitenciário que a consciência cristã penetrou. [...] Assim ocorreu a culpabilização do crime, cujos efeitos se fazem sentir em outros campos: psiquiatria, criminologia. (FOUCAULT, 2015: 84)

Como uma segunda consequência, temos que este modelo de prisão pensilvaniano criou uma exigência em que o conhecimento do prisioneiro passa a ser central. Toda uma vigilância se estabelece não propriamente para garantir que a pena seja cumprida, mas 
para tornar possível saber o que é o mais fundamental: se a transformação moral do criminoso está ocorrendo da forma devida. Desse modo, temos a transformação do próprio estatuto da pena aplicada: “A pena já não era somente um ato que se cumpria, era um processo em andamento, cujos efeitos sobre aquele que era seu objeto precisavam ser controlados" (FOUCAULT, 2015: 84). Trata-se então de uma transformação que historicamente descortinou todo um campo de saberes possíveis que servirão de instrumentos para esse poder moralizador: os saberes psicopatológicos, criminológicos, sociológicos, etc.

Dentro de um contexto tão específico e determinado de surgimento, fica a questão de como o modelo penitenciário pôde se expandir de forma tão desenfreada por várias outras partes do mundo e em contextos tão diferentes daquele de sua emergência. A resposta pode ser encontrada no próprio modo como Foucault passa a formular a questão: "Qual é o pano de fundo econômico, político e social que possibilitou essa emergência do penitenciário, essa recristianização progressiva do crime?” (FOUCAULT, 2015: 86)

\section{Penitência, capitalismo e moralidade}

O modelo penitenciário que teve seu nascimento nas colônias da América, que foi tão amplamente imitado a ponto de perder os traços de sua localização originária e de sua origem religiosa, não pode ser analisado senão pela série de acontecimentos mais amplos da qual ele é contemporâneo. Foucault irá indicar que a expansão da forma-prisão como mecanismo central do sistema penal em regiões tão distintas estará intimamente relacionada a transformações na ordem do próprio regime de produção e distribuição de riquezas imposto pelo capitalismo. A que corresponde, então, essa proliferação?

De acordo com Foucault, o desenvolvimento industrial colocou de forma maciça e direta o aparato de produção em contato com aqueles que deviam fazê-lo funcionar e que a eles deviam se submeter. A maquinaria e a organização das industriais com seus grandes estoques de matéria prima, por exemplo, assim como o surgimento de grandes centros de redistribuição de mercadorias, colocaram as riquezas ao alcance dos mais incessantes ataques. Entretanto, não se trata de ataques vindos de fora, mas sim de ataques daqueles que deveriam manipular e tornar tais aparatos produtivos. Desse modo, a produção e distribuição das riquezas assume novos riscos ao se capitalizar, de modo que, em contrapartida, toda uma nova série de organismos de vigilância e correção passam a assumir lugar de preponderância. 
Trata-se não apenas de detectar o crime, mas de atacar principalmente os hábitos, os modos de ser, as condições e os instrumentos que se compreendiam como "facilitadores" da falta. Vê-se surgir assim todo um ataque, por exemplo, ao comércio de bebidas, à prostituição, aos jogos de azar; mas também a tudo aquilo que se entendia como "falhas morais", como a preguiça, a devassidão, etc. Contra tudo isso, não se trata apenas de atuar pela sanção penal, mas sim de se instituir um sistema mais positivo e continuo que possa se estabelecer justamente na fronteira entre a penalidade e a moralidade. Assim, como dirá Harcourt:

A moralização, pois, faz parte de um processo econômico. É preciso impedir que os ilegalismos prejudiquem a propriedade material, as mercadorias, e os interesses da burguesia - inclusive dos próprios trabalhadores, visto que sua força de trabalho pertence à burguesia capitalista. (HARCOURT, 2015: 272)

Deste modo, entre o trabalhador e o aparato de produção não basta apenas uma lei negativa de repressão da depredação, pois é preciso também que o próprio operário seja moralizado para evitar a dissipação de sua força de trabalho.

[...] daí, enfim, uma imensa campanha de moralização operária. Essa campanha definiu como 'dissipação' o que queria debelar, e como 'regularidade' o que queria estabelecer: um corpo operário concentrado, aplicado, ajustado ao tempo da produção, fornecendo exatamente a força necessária. (FOUCAULT, 2015: 237)

Ora, isso explica a lapidar afirmação foucaultiana de que: “A história da moral deve ater-se inteiramente a essa questão da localização e do deslocamento da riqueza" (FOUCAULT, 2015: 101). Eis então o modo pelo qual a prisão e todo seu caráter penitenciário e moral pôde se expandir às sociedades que se defrontaram com as transformações da dinâmica das riquezas impostas pelo modo capitalista de produção e distribuição. Desse modo: "Se a prisão, com suas particularidades geográficas e religiosas, pôde inserir-se no sistema penal, foi porque, na implementação de suas formas próprias de poder político, o capitalismo utilizou a coerção". (FOUCAULT, 2015: 103).

Então, o que vemos é que, por mais que o penitenciário se estabeleça no regime de representações sociais como excluído das relações de produção social, ao nível das táticas penais há toda uma rede "exterior" ao funcionamento das prisões, mas altamente conectada a ela, que torna possível sua existência enquanto tal. Na verdade, temos aí um elemento excessivamente ligado, articulado e filiado a um conjunto heterogêneo de transformações históricas formadoras das "condições de aceitabilidade" que fizeram da prisão em sua dimensão penitenciária a forma por excelência da reclusão penal nas sociedades ocidentais. Foi a partir desse processo que os grupos religiosos nãoconformistas em sua dissidência em relação às políticas punitivas do Estado inglês 
puderam exercer como que uma inversão do poder. Se num certo momento eles foram os dissidentes e, a seu modo, estabeleceram suas conexões e foram realocados em seus jogos de articulação a partir das circunstâncias apresentadas, posteriormente - a partir de todas as transformações aqui expostas - foi o próprio Estado que se viu tomado pela exigência de moralização aos moldes desses grupos religiosos. Nas palavras de Foucault:

Foram esses grupos não conformistas e religiosos que, a partir de fora, impuseram essa conexão ao Estado, exigiram que o Estado a implementasse. Propuseram moralizar a sociedade, a despeito do Estado ou, de qualquer modo, com a ajuda dele, casos ele aceitasse, e, no momento em que quiseram moralizar a sociedade, verificou-se que, na verdade, eles estatizavam a moral e fizeram do Estado o agente principal da moralização. (FOUCAULT, 2015: 104)

\section{Da transgressão à dissidência}

Ao final de sua aula de 7 de Fevereiro de 1973 de A Sociedade Punitiva, Foucault irá apontar como alguns movimentos à época na Europa e nos Estados Unidos (como a luta pelo direito ao aborto, pela constituição de grupos sexuais não familiares, pela ociosidade, etc.) exercem uma certa relação de simetria com essa dissidência religiosa do século XVIII. Seriam, na verdade, movimentos atuais de "dissidência moral" que operariam uma simetria inversa ao que o século XVIII uniu:

[...] ou seja, todos aqueles que lutam pela descriminalização das infrações penais ou contra o atual funcionamento do sistema penal - em certo sentido fazem o trabalho simétrico e inverso do trabalho feito no século XVIII pelos agentes da dissidência religiosa que assumiam a tarefa de interligar moral, produção capitalista e aparato estatal. (FOUCAULT, 2015: 104)

Aqui, então, esses grupos têm a função de "desfazer o arranjo" e "desatar o nó" que a modernidade estabeleceu entre esses três elementos: moral, capitalismo e aparato estatal. Nesse sentido, não se trata apenas de um "não conformismo" que ignora a lei ou busca torná-la irreal em nome de uma transgressão. Lutar contra a coerção não é o mesmo que transpor um interdito, aponta Foucault. Se, por um lado, no caso deste último, tratase de tornar uma lei irreal e impotente num momento; por outro lado, entrar em dissidência diz respeito ao ataque aos sistemas de junções e às articulações táticas que constituíram a moral econômico-política da modernidade. Desse modo, Foucault é taxativo a respeito da diferença crucial entre "praticar a transgressão" e "entrar em dissidência":

Lutar contra a coerção não é a mesma coisa que transpor o interdito, uma coisa não pode ser confundida com a outra. Praticar a transgressão é tornar a lei irreal e impotente num momento e num lugar, para uma pessoa; entrar em dissidência é atacar essa conexão, essa coerção. (FOUCAULT, 2015: 105). 
Vê-se, deste modo, que a noção de dissidência estabelecida como noção política está conectada ao próprio entendimento das relações táticas do poder tal como foram formuladas a partir do conceito de guerra civil. Trata-se, pois, da indicação de como essas lutas contemporâneas operam ao nível das inversões táticas, dos jogos estratégicos, das conexões, etc. É nessa medida que podemos ler, em A Sociedade Punitiva, uma passagem da transgressão à dissidência .

\section{A dissidência antipsiquiátrica: a insurreição simuladora da histeria}

Evidentemente, não veremos mais a referência ao termo dissidência por muito tempo nos escritos de Foucault - visto, inclusive, que este uso se mantém reservado à análise realizada em A Sociedade Punitiva. Entretanto, os efeitos desse movimento "autocrítico" na ordenação de seu pensamento político são facilmente constatados na sequência da trajetória foucaultiana se nos colocarmos atentos a eles. A ênfase nos jogos de relação e na dispersão ordenada do poder e do revide assumem a dianteira em detrimento ao pensamento do limite e da transgressão. Como exemplo, podemos citar a leitura política de Foucault do "fenômeno histérico" no século XIX - situado por ele como uma verdadeira luta antipsiquiátrica. Ele aponta que - contra o sobrepoder psiquiátrico que se colocava como detentor da verdade da loucura e, assim, como agente de imposição do que era o real - a histeria, fenômeno marcado pela diversidade de sintomas e pela irregularidade de suas manifestações, teria desautorizado esse sobrepoder a partir da inscrição forçosa do problema da simulação no cerne dos jogos em que se entrecruzavam a cura, a verdade e o poder psiquiátrico.

É a partir dessa história da conexão entre a cura, o poder e a verdade na psiquiatria que podemos nos situar em relação à dimensão política que a simulação histérica operou e que marcou seu embate asilar no século XIX. Primeiramente, podemos apontar como tal relação se dava na forma particular da "cura clássica" da loucura que teve lugar durante os séculos XVII-XVIII e no início do século XIX. Como exemplo, Foucault cita o caso de um paciente de Pinel que se acreditava perseguido pelos revolucionários franceses e que estava prestes a ser levado para o tribunal e decorrentemente à morte. Ao passo que, frente a tal delírio, Pinel tratou de organizar em torno do paciente um "pseudoprocesso" com "pseudojuízes" que teatralizaram seu julgamento, no qual foi finalmente absolvido. Tal teatralização, apontou Pinel, teria por vez sanado o delírio e levado o paciente finalmente à cura. Há também um caso exemplar de tal "cura clássica" retirado dos relatos 
de Joseph Mason Cox no início do século XIX. O paciente em questão nesse caso acreditava que teria sido levado por sua "atenção demasiado concentrada em objetos de comércio" a sofrer de todo o tipo de doença, em especial a que se chamava à época de "sarna disseminada". Tal doença dizia respeito a uma infecção de sarna que não havia chegado ao seu fim e que então havia se espalhado pelo organismo e teria se traduzido em uma série de sintomas. De acordo com a medicina clássica, a cura de tal doença decorreria de fazê-la primeiramente eclodir para então poder tratá-la. Cox relata que inicialmente há uma tentativa de fazer o louco entender que não há nenhum tipo de doença que o acomete, o que evidentemente não tem o resultado esperado, uma vez que não há dissuasão alguma em contrário e o delírio permanece. O procedimento que se segue é lapidar dos mecanismos em jogo para os procedimentos da "cura clássica":

[...] Resolveu-se então realizar uma consulta solene com vários médicos reunidos, os quais, depois de examiná-lo bem e de concordarem com a necessidade de entrar nas ideias do doente, decidiram unanimemente que sua conjectura era bem fundada e que era absolutamente necessário fazer a sarna manifestar-se novamente. Em consequência disso, prescreveram-lhe aplicações rubefacientes, por meio das quais surgiram sucessivamente em diferentes partes do corpo um grande número de botões, para cuja cura só foram necessárias lavagens bem simples; mas em sua administração, fingiram tomar muitas precauções para não causar uma nova disseminação. Esse tratamento prolongado por algumas semanas teve muito bom resultado. $O$ doente ficou completamente curado e recuperou, com sua razão e sua saúde, todas as faculdades do seu espirito.' (COX apud FOUCAULT, 2006b: 161)

É dessa forma que vemos que a cura é obtida por uma espécie de "satisfação do delírio" que encontra por meio desse "teatro do real" uma via para, ao mesmo tempo, se efetuar e se desfazer. Aqui, a loucura consiste fundamentalmente numa crença equívoca, numa ilusão ou erro em relação à realidade, sendo suposto desta forma que uma vez sanado o erro será sanada também a doença.

Contudo, o erro do louco se diferencia fundamentalmente das demais formas de erro. É preciso destacar, como lembra Foucault, que não é propriamente por sua "extravagância" que o erro do louco é particular aos demais. François Leuret - um eminente psiquiatra de sua época, dizia, por exemplo, que não havia muita diferença entre os delírios de uma de suas pacientes na Salpêtrière e as indicações filosóficas de Descartes:

[...] dizia [a paciente] ter em seu ventre bispos que realizavam um concílio [...] Descartes dava como certo que a glândula pineal é um espelho em que vem se refletir a imagem dos corpos exteriores [...]. Porventura uma dessas asserções é mais bem provada do que a outra? (LEURET apud FOUCAULT, 2006b: 174) 
O que há de particular no erro do louco, portanto, não é sua extravagância, mas sim o fato deste erro não poder ser desfeito pela mera "demonstração"; e isto de modo que o louco "é alguém para o qual a demonstração não produz a verdade" (FOUCAULT, 2006b: 161). Assim, a dissolução de seu erro não se dará pela invalidação de seu juízo ao ser demonstrado sua não-correspondência com uma realidade dada. O que vemos a partir dos casos de Pinel e Cox é algo de outra ordem:

[...] deixa-se valer como verdadeiro esse juizo que é falso e, em contrapartida, transforma-se a realidade de maneira que ela venha se ajustar ao juizo louco, ao juizo errôneo. [...] a partir desse momento, o que está no espírito coincidindo com o que está na realidade não há mais erro e portanto não há mais loucura. (FOUCAULT, 2006b: 162).

Trata-se, desse modo, não de uma retificação ao real estabelecido, mas de uma manipulação da realidade na medida em que esta possa se insinuar nas entranhas do delírio até que este fique "repleto de realidade" e possa, pela boa condução, dissolver-se e deixar de ser erro. Nas palavras de Foucault: "faz-se a realidade delirar de maneira que o delírio não seja mais delírio; desengana-se o delírio de maneira que ele não se engana mais" (id: 162). O psiquiatra, dessa forma, diferencia-se do professor e do cientista, na medida em que o que fazem essas figuras é uma manipulação do juízo por meio de proposições, demonstrando assim o equívoco. Algo absolutamente distinto faz o psiquiatra: este manipula não o juízo, mas a realidade, de modo que possa então, a partir desse manejo, fazer com que "o erro se torne verdade".

O médico, nesse gênero de operação, é o intermediário, a pessoa ambivalente que [por um lado] olha para a realidade e a manipula e, por outro, olha para a verdade e o erro e dá um jeito para que a forma da realidade baixe ao nível do erro para transformá-lo assim em verdade. (FOUCAULT, 2006b: 63)

Ora, a relação entre cura, realidade e verdade que se estabelecerá pouco mais tarde na psiquiatria asilar de caráter disciplinar é algo muito distante disso. Nesse momento o psiquiatra não se portara mais como "o senhor ambíguo da realidade e da verdade" e tampouco como o "contrabandista do real", manipulando-o em favor do delírio e de sua cura. O psiquiatra asilar, dirá Foucault, é aquele que, de uma vez por todas, já passou para "o lado da realidade" e não mais habita o espaço limiar entre o delírio e o real que fora ocupado por Pinel e Mason Cox, por exemplo. Estabelecida como agente de um real exterior ao delírio, cabe a esta psiquiatria a intensificação da força coativa de uma realidade já dada. E isto de modo que, aqui, já não há mais qualquer negociação possível com o delírio. 
O psiquiatra é aquele que [...] deve proporcionar ao real o suplemento de poder necessário para se impor à loucura e, inversamente, o psiquiatra vai ser aquele que deve tirar da loucura o poder de subtrair-se ao real. [...] a partir do século XIX o psiquiatra é um fator de intensificação do real e é o agente de um sobrepoder do real, ao passo que, na época clássica, de certo modo, ele era o agente de um poder de irrealização da realidade. (FOUCAULT, 2006b: 164).

Como agente absoluto do real, este poder psiquiátrico realocará o problema da verdade em outro lugar, uma vez que agora ela se encontrará subtraída da relação entre médico e paciente, passando a habitar de antemão o próprio interior da psiquiatria e sua autojustificação permanente. Desse modo:

[...] em vez de irromper no choque entre médico e doente, o poder psiquiátrico coloca a questão da verdade somente no interior dele próprio. Ele a faz sua de saída e de uma vez por todas, constituindo-se como uma ciência médica e clínica. Ou seja, em vez de estar em jogo na cura, o problema da verdade foi resolvido de uma vez por todas pela prática psiquiátrica, a partir do momento em que ela se deu como estatuto ser uma prática médica e como fundamento ser uma aplicação de uma ciência psiquiátrica. (FOUCAULT, 2006b: 164).

Estabelecida de forma definitiva como a agente exclusiva da verdade, a psiquiatria asilar transformará a cura num derradeiro ato de imposição. Este mecanismo caracterizará o que Foucault vai entender como sendo o fundamento do "poder psiquiátrico". Assim, ele o definirá da seguinte maneira: “o poder psiquiátrico é esse suplemento de poder pelo qual o real é imposto à loucura em nome de uma verdade detida de uma vez por todas por esse poder sob o nome de ciência médica, de psiquiatria" (id: 164-5).

Isso nos permite compreender, portanto, a curiosa relação que a psiquiatria da época estabelece com seus discursos de verdade. É notória a proliferação de uma série de discursos de caráter classificatórios e clínicos, por exemplo. Trata-se, por um lado, da dimensão nosológica desses discursos, uma vez que essa psiquiatria se propunha como uma espécie de saber análogo à verdade e ao sistema de classificação médicos. Por outro lado, vemos o problema da etiologia se inscrever na psiquiatria por meio de toda uma série de tentativas de estabelecimento de um saber anatomopatológico que coloque em questão os substratos orgânicos da loucura. Aqui, a psiquiatria se articula a toda uma dimensão fisiopatológica que deveria ofertar uma garantia materialista a seu estatuto de ciência.

Em contrapartida - ao mesmo tempo em que havia uma adesão a toda essa série de discursos - não havia, em sua prática, uma correspondência e um emprego das implicações derivadas desses saberes. Assim: “[...] é ao abrigo desses dois discursos que 
a prática psiquiátrica se desenvolvia, mas ela nunca se servia deles, ou só se servia por referência, por um sistema de remissões e, de certo modo, por vinculação." (FOUCAULT, 2006b: 166).

Não há, portanto, na psiquiatria do século XIX o emprego desses saberes na regulação de suas práticas.

As distribuições asilares, a maneira como os doentes eram classificados, como eram repartidos no asilo, como lhes era dado um regime, como lhes eram impostas tarefas, como se declarava que eles estavam curados ou doentes, que eram curáveis ou incuráveis, no fundo, não levavam em conta esses dois discursos. Esses dois discursos eram simplesmente garantias de verdade de uma prática psiquiátrica que queria que a verdade the fosse dada de uma vez por todas e não fosse mais questionada. (FOUCAULT, 2006b: 166)

Não é que se possa dizer que há aqui uma "disfunção" entre o discurso e a prática psiquiátricas, pois a sua "ausência de relação" garantia a funcionalidade da prática terapêutica como um lugar em que, ali, a verdade nunca seria posta em questão. Essa “distância", portanto, permite a consolidação sem ruídos de uma relação em que a imposição do real possa se dar sem os constrangimentos de qualquer questionamento possível. Esvaziamento, portanto, do espaço da "justa” entre o médico e o paciente. Empoderamento, em contrapartida, do psiquiatra como agente exclusivo do real, da verdade e da cura.

Entretanto, é justamente aí - nesse espaço em que a verdade nunca é colocada em questão - que o problema da simulação surgirá como uma força turbulenta inultrapassável. Mas o que se deve entender por "problema da simulação"? Primeiramente, é preciso especificar do que se fala quando falamos de "simulação" nesse contexto: não se trata de se passar por louco quando de fato não se é (questão, portanto, do fingimento). Este tipo de simulação em nada põe em risco o dispositivo psiquiátrico, uma vez que conserva em todo seu funcionamento os mecanismos de atuação da prática psiquiátrica que - neste caso - apenas estariam atuando sobre um "alvo" equivocado mantendo conservada, assim, seu lugar de agente absoluto do real e da verdade frente à loucura "legitima". Além do mais, esse tipo de estratégia de "enganação" ocorre em várias ordens do saber médico sem que, contudo, a prática médica seja colocada em questão a partir disso. Dessa forma, a simulação que Foucault anuncia aqui diz respeito a outra ordem:

[...] a simulação que foi o problema histórico da psiquiatria no século XIX é a simulação interna à loucura, isto é, essa simulação que a loucura exerce em relação a si mesma, a maneira como a loucura simula a loucura, a maneira como a histeria simula a histeria, a maneira como um sintoma verdadeiro é uma certa maneira de 
mentir, a maneira como um falso sintoma é uma maneira de estar verdadeiramente doente. Foi tudo isso que constituiu para a psiquiatria do século XIX o problema insolúvel, o limite e, finalmente, o fracasso a partir do qual ia se produzir certo número de ressurgências. (FOUCAULT, 2006b: 167-8)

Essa simulação "interna" à loucura vai constituir um problema que atravessará a história da psiquiatria no século XIX, uma vez que, se esta baseou sua prática a partir da tomada do lugar da verdade, o "jogo de mil faces" da simulação faz esse lugar rodar no vazio. E isto de modo que, frente a uma loucura definida pela constante variação de si própria e pela constante renovação do modo de ser louco, a psiquiatria vê-se destituída de suas garantias nosológicas, anatomofisiológicas, médicas, etc. Se o lugar de verdade da psiquiatria garantia o seu direito de ser o agente absoluto do real, a colocação em xeque deste lugar faz evidenciar o próprio poder psiquiátrico como artificial e arbitrário.

Assim, a simulação manipula a própria loucura e faz com que o direito à soberania da realidade que funda o poder psiquiátrico se apresente como uma espécie de "delírio da razão". Dessa maneira, temos que a "mentira da simulação" irrompe como uma força que se encontrará perpetuamente em dissidência ao poder psiquiátrico. Como destaca Foucault, é este "antipoder" simulador justamente o ponto de inflexão de uma crise fundamental:

[...] a grande crise da psiquiatria asilar, a que eclodiu no final do século XIX, mais ou menos em 1880, que aparece quando se percebe que, diante da grande taumaturgia de Charcot, todos os sintomas estudados por ele eram por ele suscitados a partir da simulação de seus doentes, de modo que o problema da verdade tenha sido imposto à psiquiatria pelos loucos. (FOUCAULT, 2006b: 169, grifo meu)

Ora, esta leitura política da simulação nos permite extrair uma série de considerações importantes a respeito do fenômeno da histeria. Primeiramente, o fato de que não se trata aí de um "assunto de sintoma" ou da histeria como "a grande doença do século XIX” que teria desaparecido com seu fim. É preciso demarcar que, a partir dessa leitura de Foucault, podemos compreender a histeria como um fenômeno de luta correlativo ao poder asilar: "Foi efetivamente o processo pelo qual os enfermos tentavam escapar ao poder psiquiátrico; foi um fenômeno de luta, e não um fenômeno patológico" (FOUCAULT, 2006b: 169). É dessa forma que o caráter coletivo da histeria pode ser entendido em sua dimensão de batalha: "É portanto como processo, não apenas de luta dos doentes contra o poder psiquiátrico, mas de luta no interior do próprio sistema psiquiátrico, do sistema asilar, que é preciso compreender o fenômeno geral da simulação no século XIX” (FOUCAULT, 2006b:170, grifo meu). 
Foucault destaca que teria sido justamente pela força desses processos que a questão da verdade - que foi “tomada de assalto" pelo poder psiquiátrico - é reintroduzida à força em seu cerne. Assim, à luz dessa perspectiva, a psicanálise - por exemplo - pode ser interpretada como o "primeiro grande recuo da psiquiatria" frente a toda essa disrupção simuladora. E isto de modo que:

Em todo caso, não é tanto a Freud que se deve creditar a primeira despsiquiatrização. A primeira despsiquiatrização, o primeiro momento que fez titubear o poder psiquiátrico acerca da questão da verdade, é a esse grupo de simuladores e simuladoras que o devemos. Eles é que, com suas mentiras, ludibriaram um poder psiquiátrico que, para poder ser agente da realidade, pretendia-se detentor da verdade e se recusava a colocar, no interior da prática e da terapia psiquiátrica, a questão do que há de verdadeiro na loucura. Houve o que poderíamos chamar de uma grande insurreição simuladora que percorreu todo o mundo asilar no século XIX e cujo foco constante, perpetuamente aceso, foi a Salpêtrière, asilo de mulheres. (FOUCAULT, 2006b: 170-1, grifo meu)

Eis a histeria, então, como “o verso militante do poder psiquiátrico”. Deslocamento este que permite a Foucault, em seu entendimento, "fazer uma história da psiquiatria que não gravitará mais em torno da psiquiatria e de seu saber, mas que gravitará enfim em torno dos loucos" (id: 171).

\section{Considerações}

Creio que a partir de uma cartografia das dissidências nos escritos de Foucault podemos extrair uma singularidade política de seus procedimentos genealógicos. Não nos seria estranho, por exemplo, se encontrássemos nas "vidas infames" salientadas por Foucault (2006a) - essas "existências-clarão" que entram em dissidência com o poder pelo simples fato de existirem enquanto tal - as diretrizes de uma nova imaginação política que daí veríamos emergir. A relação entre dissidência e infâmia ainda está para ser analisada, mas certamente sua "metodologia" é aquela dos saberes dominados destacados na primeira aula do curso Em Defesa da Sociedade (2010).

Esses "saberes dominados" dizem respeito aos conteúdos históricos que foram sepultados por grandes sistemas de pensamento. Dizem respeito também à série de saberes desqualificados como incompetentes ou insuficientemente elaborados, saberes que seriam ingênuos e hierarquicamente inferiores e que não estabelecem o mínimo requerido para seu reconhecimento ou sua cientificidade. Isso não quer dizer que sejam saberes do senso comum ou pautados por um bom senso geral, pois indicam saberes altamente singulares, particulares e locais. São "saberes diferenciais" e incapazes de 
unanimidades, devendo a sua força à dimensão em que se opõem a todos os outros saberes "rigorosos" que os circundam - em relação aos quais, como que sem perceber, acabam por realizar a crítica.

Ora, mas não é exatamente em relação a isso que nessa ocasião Foucault situará o que é o trabalho genealógico? Este seria engajado em efetuar uma "redescoberta exata das lutas e memória bruta dos combates" (FOUCAULT, 2010: 9); e isto por via de um acoplamento entre os artifícios da erudição e esses "saberes menores" - acoplamento este que eliminaria de cena a "tirania dos discursos englobantes" e todo silenciamento que deles advêm. Trata-se de ativar os saberes locais, descontínuos, desqualificados e não legitimados contra a instância teórica unitária que pretenderia depurá-los, hierarquizá-los, ordená-los em nome de um conhecimento verdadeiro e em nome dos direitos de uma ciência detida por alguns.

Articulada às memórias locais e às lutas silenciadas pelos "grandes saberes", a genealogia será então um exercício de liberação dos "saberes menores" contra o julgo de sua deslegitimação, fazendo de sua história um instrumento de luta direcionado ao próprio presente. É dessa forma que sua empreitada jamais poderá ser cúmplice da indignidade da neutralidade, pois será sempre intensamente implicada no uso interessado da história contra tudo aquilo que em nós impede nossa descontinuidade e ruptura com os efeitos estabilizados do poder no presente. Dessa forma, creio que podemos extrair dos múltiplos trabalhos que compartilham essas implicações com as diversas genealogias empreendidas por Foucault um certo número de ferramentas que valham a uma entrada em dissidência frente ao nosso tempo.

\section{Referências}

DIDI-HUBERMAN, G. Invenção da Histeria: Charcot e a iconografia fotográfica da Salpêtrière. Tradução de Vera Ribeiro. Rio de Janeiro, RJ: Contraponto, 2015a.

FOUCAUlT, M. A Sociedade Punitiva: Curso no Collège de France (1972-1973). Tradução de Ivone C. Benedetti. São Paulo, SP: Editora WMF Martins Fontes, $2015 b$.

A Verdade e as Formas Jurídicas. Tradução: Roberto Cabral de Melo Machado; Eduardo Jardim Morais. $3{ }^{\text {a }}$ edição. $5^{\text {a }}$ reimpressão. Rio de Janeiro, RJ: NAU Editora, 2011.

A vida dos homens infame. In: . Ditos e Escritos, v. IV: Estratégia, Podersaber. Tradução de Vera Lúcia Avellar Ribeiro. - 2 ed.- Rio de Janeiro: Forense Universitária, 2006a. 
Em Defesa da Sociedade: Curso dado no Collège de France (1975-1976). $2^{\mathrm{a}}$ edição. Tradução de Maria Ermantina Galvão. São Paulo, SP: Editora WMF Martins Fontes, 2010.

O Poder Psiquiátrico: Curso dado no Collège de France (1973-1974). $2^{\mathrm{a}}$ tiragem. Tradução de Eduardo Brandão. São Paulo, SP: Martins Fontes, 2006b.

Prefácio (Folie et déraison). In : MOTTA, M. B. (org.). Ditos e Escritos, v. I: Problematização do sujeito: psicologia, psiquiatria e psicanálise. Tradução de Vera Lucia Avellar Ribeiro. $2^{a}$ edição. $1^{a}$ reimpressão. Rio de Janeiro, RJ: Forense Universitária, 2006c, p. 152-161.

Prefácio à Transgressão. In : MOTTA, M. B. (org.). Ditos e Escritos, v. I: Problematização do sujeito: psicologia, psiquiatria e psicanálise. Tradução de Vera Lucia Avellar Ribeiro. 2a edição. $1^{a}$ reimpressão. Rio de Janeiro, RJ: Forense Universitária, 2006c, p. 152-161.

. Vigiar e Punir: Nascimento da prisão. 36ª ed. Petrópolis, RJ: Vozes, 2009.

HARCOURT, B. Situação do Curso. In: FOUCAULT, M. A Sociedade Punitiva: Curso no Collège de France (1972-1973). Tradução de Ivone C. Benedetti. São Paulo, SP: Editora WMF Martins Fontes, 2015c, p. 241-281.

LÉVI-STRAUSS, C. Tristes Trópicos. Tradução de Wilson Martins. São Paulo, SP: Editora Anhembi Limitada, 1957.

SARDINHA, D. As duas ontologias críticas de Foucault: da transgressão à ética. Trans/Form/Ação, Marília, v. 33, n. 2, p. 177-192, 2010. Disponível em: http://www.scielo.br/scielo.php?script=sci_arttext\&pid=S0101-

31732010000200011\&lng=en\&nrm=iso . Acesso em: 01 de Maio de 2021.

Mateus Thomaz Bayer Doutorando pelo Programa de Pós-Graduação em Psicologia da Universidade Federal do Rio de Janeiro (PPGP-UFRJ). Professor substituto do Instituto de Psicologia da Universidade Federal do Rio de Janeiro (IP-UFRJ)

E-mail: mateusthomaz@gmail.com Orcid: https://orcid.org/0000-0002-5938-6628

\footnotetext{
${ }^{\text {i }}$ Como exemplo desta indicação, podemos destacar a passagem de Georges Didi-Huberman em seu $A$ Invenção da Histeria - trabalho, de todo, muito marcado pelas teses de Foucault aqui expostas: "Restamnos hoje as séries de imagens da Iconografia fotográfica da Salpêtrière. Está tudo ali: poses, crises, gritos, 'atitudes passionais', 'crucificações', 'êxtases', todas as posturas do delírio. Tudo parece estar presente, pois a situação fotográfica cristalizava idealmente a ligação entre a fantasia histérica e uma fantasia do saber." (DIDI-HUBERMAN, 2015: 15)
} 